\title{
VALUATION OF CULTURAL GOODS: EVALUATION OF PERSPECTIVE METHODS
}

\author{
Luboš SMRČKA - Eva KISLINGEROVÁ - Jiř́ STROUHAL - Klára KUBÍČKOVÁ - \\ Markéta KUBÍČKOVÁ ${ }^{6}$ \\ University of Economics Prague
}

\begin{abstract}
Valuation of cultural assets represents a very actual topic not widely discussed within contemporary accounting and financial research. Main motivation of this paper is therefore to provide an empirical evidence of the methods for valuation of cultural and artistic goods. In general, any method for valuating cultural and artistic goods or institutions cannot bring results as objective as those available to valuate assets in the real market economy. Within this paper we did focused on valuation on a specific case of cultural institutions (theatre, museum) and also we aimed to analyse the economic impacts of cultural organizations.
\end{abstract}

\section{KEY WORDS}

cultural goods, creative industry, valuation methods, economic consequences, state grant policy, Czech Republic

\section{INTRODUCTION}

Our truly fundamental problem in trying to define the value of cultural goods from an economic perspective is the fact that we are uncertain of even the absolutely simplest basic terms in this field. And we can apply scientific procedures and methods only with difficulty in areas where precisely defined terms are unavailable. Without a firm spot, we cannot move the earth; but likewise, we can reach a consensus only with difficulty if each of us attributes to all basic terms such as value, cultural good, and public interest or art either completely or perhaps just a little different meaning.

Yet why one should be concerned with the economic contexts of cultural or artistic goods when the issue is clearly a problem which may indeed concern the economy, but only marginally? One sees the appearance of a social demand, primarily from political circles, that economics (as an economic science connecting the exact field of mathematics on one hand and social sciences on the other) provide governments or municipalities with certain scales for evaluating the success of spending

\footnotetext{
${ }^{6}$ Correspondence address:

Luboš Smrčka, doc. Ing. CSc.; University of Economics Prague, Department of Business Economics, W. Churchill Square 4, 13067 Prague 3, email: lubos.smrcka@vse.cz

Eva Kislingerová, prof. Ing. CSc.; University of Economics Prague, Department of Business Economics, W. Churchill

Square 4, 13067 Prague 3, email: eva.kislingerova@vse.cz

Jiří Strouhal, doc. Ing. Ph.D.; University of Economics Prague, Department of Business Economics, W. Churchill

Square 4, 13067 Prague 3, email: jiri.strouhal@ vse.cz

Klára Kubíčková, Ing.; University of Economics Prague - student team member

Markéta Kubíčková, Ing.; University of Economics Prague - student team member
} 
public funds aimed especially at supporting culture or performing arts. The demand concerning expenses for maintaining monuments and the so called cultural heritage is less vociferous.

Nevertheless, it too exists. The administrations of states, regions and municipalities admit that they lack the instruments that would suitably and indubitably enable reaching political decisions as to the apportionment of public funds in the direction of culture and art. Politicians require these tools from economists, as they themselves are frequently the targets of criticism for the lack of objectivity and readability of their decision-making. In the Czech environment which, like many other countries, faces acute problems in the field of public finances, this demand is very strong.

\section{PROBLEM FORMULATION}

We use as our departure point the hypothesis that it is possible to create various mechanisms enabling at least elementary assessment of cultural and artistic goods in terms of their value and thus enable at least a retrospective assessment of adequacy of expended funds. This hypothesis is quite bold; in fact, considerable skepticism, which has been summarized by many authors to date, prevails in this matter (O'Brien, 2010), and we shall also mention the majority of the most frequent arguments for the impossibility of the task.

We call the set of such methods (in accordance with the mechanisms for the support of scientific research that is standard in the Czech Republic) the certified method for valuating cultural and artistic goods. Now, we will not venture to construct this method, but rather define aspects that it has to take into consideration from the perspective of its own economic efficiency. Several of them appear in certain previous works (Kislingerová, 2013; Raabová, 2011).

Kislingerová (2013) presents a comprehensive summary of numerous aspects of the problem of creating mechanisms for evaluating the efficiency of public funds expended in the area of culture and art. In the following passages, we will repeatedly refer to this study. Besides this work, the team of the Arts and Theatre Institute in Prague (Raabová, 2011) presents a proposal for certified methods for calculating the economic impacts of cultural organizations. These are two attempts to examine what is in principle the same problem from different angles. The first procedure attempts to gain information on the value of a cultural or artistic good (work, activity, existence of a museum or theatre), the second attempts to ascertain at least the real economic impacts of the existence of cultural institutions, i.e. not only directly, but also mediated in various ways. We will subsequently ground our observations also on this research.

This problem is, of course, not only the specific theme of the Czech Republic - on the contrary, it has a considerable tradition in the Anglo-Saxon world. This tradition is developed especially in connection with the development and support of the creative industry. Cikánek (2009) gives an elegant overview of this branch, although the work of Florida (2002) (in the area of defining the creative industry) or authors such as Alpizar et al. (1998) (when explaining the possibility of experimenting with selection mechanisms) are among the fundamental works on this theme.

Even on the basis of these departure points, we need to admit that creating a certified methodology that could generally be applied to the field of art and culture is practically unimaginable. It will therefore be necessary to proceed not with the intention of creating a single mechanism, but rather to define an idea framework. Within it, detailed mechanisms specified for specific cultural or artistic goods, or rather aggregates of goods, will then be defined. 


\section{DETERMINING THE VALUE OF CULTURAL GOODS}

The first and possibly the most serious trouble is the fact that a mere minority of cultural goods has a market price, which only partially covers the overall value of the cultural goods. We can easily demonstrate our statement on two examples. Let us say we have at our disposal an important painting by a renowned artist - perhaps The Scream by Norwegian painter Edvard Munch. The painting has its market price, which was exactly set during the last auction of this masterpiece. Yet does it also express its value as a cultural object? Let us justly be afraid it does not. The painting became the foundation of many other works of art, which follow it, use its main motif both in the area of visual arts or in literature and film. If - hypothetically - the world society (or humankind, to put nicely) was forced to choose: either you collect a certain sum of money or this painting will be destroyed forever, what result would we arrive at? What total sum would the humankind be willing to sacrifice for this indisputably unique cultural object? We cannot give it a try; hence we have no answer that would withstand criticism. Moreover, the situation itself would certainly have a number of possible variations, each of them likely to offer a wide scale of answers. For instance, the outcome would depend on whether the situation was a one-off event or whether the humankind would have to face the same threat every now and then and was forced to pay for Da Vinci's Mona Lisa or the Great Pyramid of Giza.

Let us imagine another option relating directly to the Czech reality. The historic building of the National Theatre will fall into ruins unless the Czechs collect among themselves a larger sum - say 400 million EUR. Moreover, they would have to contribute with 40 millions from their own pockets to the venue's further operation every year, rather than paying more or less anonymously through the tax system. Would every single citizen be truly willing to spend his or her share on such events? Everyone in the Czech Republic would have to do without forty EUR on the spot and then start giving away for EUR every year. The sum is not too large in itself and if we carried out a survey, the results would probably be quite optimistic. Yet we can only guess how many people would be willing to spend the sum in reality (their number surely being substantially lower than the survey would have suggested).

The second trouble is that we are unable to define exactly the term cultural goods. We could debate about this topic for a long time, explaining why it is so difficult to describe culture with a definition. Yet all the important facts have been said, so we can only sum up the elementary: Culture is an absolutely individual sphere (Kant, 1965), therefore its definition is different for every person, and sometimes the differences can be huge. Every individual also sees differently the importance of culture, which figures within their value system not as one phenomenon, but as hundreds or thousands of particular qualities. It therefore stands that culture is not a homogenous concept and it can denote a set of artefacts, experiences, performances and so on, where the individual components have in fact nothing in common. Apart from a concrete individual person who places those into the "culture" group (Cikánek, 2009).

The third decisive trouble related to valuing cultural goods is the fact that the very use of the term value is rather confusing in this respect - and it is particularly confusing for economists. Theoreticians and professionals alike are used to applying the term value in strictly defined and mutually related meanings. Actually, they understand it as a value common in goods and a use value. They are both an expression of the fact that every particular object, thing or machine has both a usual value given by external aspects and a use value reflected in the possibility or capacity of the owner of the object or commodity to use their goods for production or for providing services.

Here we are getting to a problematic situation - philosophy and other humanities are much more creative in the use of the word value, which causes noticeable chaos in the subsequent discussions. The economy sees value as something measurable and quantifiable by standard means that is by a 
larger or lower sum of money. Or possibly something that can be measured additionally, for instance by cash flow. Of course, this does not mean that price is set by assigning a value prior to the process of changing the owner of assets. Value is always just a thought concept in this respect, and becomes price only once it is tested by the transfer of assets through the payment of money. This too is a cause of trouble when one tries to understand the ideas concerning the valuation of cultural goods and the valuing of assets in general.

The term value (social value of a work of art or cultural good) is a key term when evaluating the relative importance of a work of art or cultural good and thus for assessing the efficiency of funds expended from public sources. Numerous fatal misunderstandings occur in this area among economists and social scientists. It is necessary to forget about terms such as exchange value, use value or usual value. In some way, we need to determine the value a particular work of art, particular artistic or cultural institution or certain artistic action has for society, in what way it influences it or moves it forward. We then have to compare this ascertained value with the public funds that have been expended for achieving the assessed result.

As we have suggested, the problem lies in the non-existence of value criteria. If the judgment of taste is entirely individual, as Kant (1965) assumes - and we have no reason to doubt it - then for all questions regarding the value of art or culture, we will necessarily have to get the same number of answers from as many respondents that we manage to approach. In that case, however, we arrive at a difficult situation and we must either choose another method (for instance, asking only experts) or delimit such approximate spaces for answer variants that would force the majority of respondents either to significantly rectify their views in order to fit the answer or desist from the task. As for the judgment of taste, Kant deduced, among other things, that it is impossible to conduct a discussion about it as he did not consider it to be a category of reason. For the same reason, we can conceive a methodology for evaluating cultural goods only with difficulty. Moreover, there is the problem of defining scale. In fact, Kislingerová (2013) draws attention to the fact that, thanks to the inability of our society to fix a monetary value to a work of art or cultural good, we tend to make a declaration about "inestimable value". In this regard, the author observes, among others, that: In fact, "inestimable" in this context does not mean "infinitely high", but far more likely "unknown" or "individually irrelevant". Let us admit that we might certainly consider the discovery of Celtic ceramics, bronze jewels and imported pieces of silver with amber to be significant and culturally important, but we would do so more likely because this is "the done thing" than because we would truly be convinced that, thanks to decorations on bowls, we would gain an insight or even develop culturally. Despite this, we will accept the statement that it is a discovery of "inestimable value". The author then observes that this phenomenon concerns many works of art and cultural goods, not only the archaeological diggings that she uses as an example.

Interestingly, we are automatically able to describe the opposite experience more precisely in connection with money - "it wasn't worth the money", "what a waste of money". This is obviously given by the fact that a certain monetary sum was paid and the comparison with the value of money for a particular individual is thus given. It therefore seems that the procedure for evaluating works or goods in terms of use or value for society is truly a difficult problem to solve, and one cannot even rely on expert opinions. We must yet again take the example from the field of financing performing arts in the Czech Republic. In Prague, the country's capital city, a discussion has been underway for practically twenty years regarding the funding of the theatre network, and even though many experts on theatre have been gradually involved in numerous evaluating commissions (due to "severance of friendly relations"), even from other cities and abroad, none of the accepted models have been recognized as being adequately functional and capable of self-reflection.

If, strictly economically, we apply the term value on the sphere of cultural goods, we obtain a "value" expressed in money, but we often use it together with other expressions that simply defy 
such application. It often happens with archaeological finds of the type that does not include artifacts, but rather jewellery or crafted objects of daily use or coins. There is, on the one hand, the value of the material (i.e. its market price) the object is made of, such as precious metal, and collectible value, which one can find out by trying to sell the object, for example at an auction. Moreover, there is historic value, often referred to as priceless. The historic value is a sui-genre value of a cultural good, too. Yet if it is so "priceless", the team that found such objects provided "priceless" benefits to humanity. If we took such statements literally, archaeologists would have to be among the wealthiest people, because they would have to be remunerated for their benefits. Which they are not. In fact, "priceless" does not mean "extremely valuable" here, but rather "unknown" or "individually irrelevant". Let us admit that we consider the finding of Celtic ceramics, bronze jewellery and imported pieces of silver with amber as important and culturally beneficial, but mainly because "it is appropriate", rather than because we are truly convinced that we might learn something from the decoration on a bowl or develop culturally. Yet we will accept the statement that the finds are "priceless". A similar paradox actually concerns a vast number of other kinds of cultural goods, not just archaeological finds.

Similarly, we may be able to unmask the notion that literature, theatre and arts in general bring something that "money cannot buy" to humankind. Though it is a true statement in itself, the fact is that the benefit for humanity is in surprising contradiction to the way individuals value it. As for them, they are not ready to pay any absolute prices for such cultural objects. It is a strange and hardly tangible contradiction between the value perceived by the society as a whole, expressed by extensive and strong evaluating proclamations, and individual value expressed by the real price people in the world of economic acts are willing to spend in terms of the money they sacrifice.

From this it follows that the way our basic communication tool, i.e. language, copes with the issue, can be a real eye-opener to some extent. If we take a closer look at some of the commonly used phrases, we find in them the very cluelessness we experience when facing the issue from the scientific point of view.

We might go on and on like this for a long time in bringing together all the arguments against the possibility to value cultural goods.

The literature concerning economic relations in the field of culture is rather scarce in the Czech Republic. In addition, the most notable works concern a related area, dealing with the question of creative industries (Cikánek, 2009). The attempt at carrying out a more detailed study of economic activities that could, according to some researchers, become the driving sector of national economies in the developed countries in the upcoming decades, is by all means quite interesting. Yet it does not contribute in any way to the solution of questions regarding the public funding of non-commercial cultural events. Similarly, it can help even less to explain the trouble with valuing cultural goods. Nevertheless, we would like to mention the work of Richard Florida, who puts forward the thesis that public funds expended to support quality culture do pay off, because they help to create an environment suitable for the development of the "creative class". It is a group of people with substantial creative skills, which we can interpret quite straightforwardly as workers able to create new methods, new objects, and new solutions. The creative class cannot exist without sufficient impulses, one their sources being art, especially quality art (Florida, 2002). Of course, one can reject such thought constructs as calculated statements built upon partial research. Similarly, we could cast into doubt the whole structure of creative industries as an artificial concept creating a uselessly complex scientific argument around events that are natural, normal and non-surprising. Although we do not have enough space here for a more detailed analysis of this question, dealing with the issue of creative industries in such a straightforward way would be too simple. 
As far as attempts at valuing cultural goods are concerned, the works describing the possibility of using some methods developed in other countries are an interesting practical incentive from the Czech area (Kubíčková, 2012ab).

\subsection{Purpose of Valuing Cultural Goods}

It would be truly misfortunate letting ourselves discourage by the complexities of valuing cultural goods from the attempts at finding a method or set of methods able to bring decent results. Keeping in mind, of course, that always, and under any combination of reasonable conditions, we need to take the results with a pinch of salt, as something auxiliary and providing us with only elementary orientation. To sum up, we can define this attitude as follows: let us keep trying to create and apply methods that will enable us to somehow value cultural goods, define its social value by transferring it to money units. Yet let us be absolutely skeptical towards any result we arrive at.

Yet why should we actually endeavor to keep searching to find something we are not sure about? Not only are we uncertain to succeed, but we know that succeeding does not equal to any thinkable result achievable by correct methods.

The answer lies in the area of public funding. Somewhat automatically, in the European context we believe that creating cultural goods (we need to note that we are not quite sure what is a cultural good and what is not) is a sphere that requires public funding, and we accept the thesis that culture cannot "make its own living" because if we left it to its own devices, it would be only commercial and pandering. For certain cultural, political and other reasons, the European society has accepted the idea that although most of its members prefer to consume mainstream and pandering culture, we need to foster other cultural areas as well, especially the arts in this context. The culture of mass consumption has thus been shifted into the area of entertainment industry, and this mass production is not primarily the aim of grants or subventions. On the other hand, the culture (again mainly the arts) that we call high is considered by the majority to be a legitimate recipient of public funds. In other words, there is general consent that this kind of culture should be granted money from public funds.

We do know for sure that any allocation of money from public resources where unambiguous and clearly defined rules cannot be set, always ends up by waste of public funds and their allocating for activities that have no direct connection with the original purpose of the subsidy or grant. Many cases are known of subventions intended to support significant art events being granted to subjects running rather commercially oriented events of little artistic value. If we had the possibility to conduct estimates of the value of cultural goods in terms of the relation between the actual public funding granted to a particular activity and the way the society values such activity, we would get some basic guidelines for the assessment of public funding.

\subsection{Attempts at Valuing Cultural Goods}

We have to admit that some of the methods at hand supposed to help us with determining the value of cultural goods are unusually sophisticated. An interesting overview from the Anglo-Saxon area was provided to the Czech researchers by the above-mentioned authors of the attempt at valuing the theatre and museum in the town of Tábor (Kubíčková, 2012ab).

Both authors chose the method of contingent valuation supplemented by Victor S. Yocco's method; using this theoretical apparatus they examined the value of the two cultural institutions in relation with the amount of public funding they receive, and the value of both institutions for individual groups of citizens, such as for theatre- and museum-goers on the one hand, and for non-goers to either venue on the other hand. 
For illustration purposes, let us quote from one of the studies' conclusion: "The survey included 121 respondents from the Tábor region and it was conducted by oral and electronic method. The first part of the survey concerned the frequency of visiting the theatre. We found out that in the last 12 months, the goers visited the theatre 5.25 times on the average. From that it follows that the Oskar Nedbal Theatre Tábor actually has quite a narrow base of regular goers who frequent it several times a year, rather than appealing to a wider spectrum of people. Furthermore, we assessed 19 statements created by Victor S. Yocco which refer to three hypothetical categories of value. According to Yocco's tool adjusted to theatre environment, theatre was valued positively, receiving an overall average of 4.96 points on a seven item scale. People appreciated most the criteria of individual value, which means for instance the fact that the theatre provides the opportunity for an artistic experience or that it is the source of pleasure and entertainment. This seems to support the idea outlined in the theoretical part that valuing culture on the basis of its economic and socioeconomic impacts is insufficient for expressing its actual value.

As regards the willingness to pay, after removing the extreme values and one anticipated protest response, the average individual willingness to pay amounted to $56.19 \mathrm{CZK}$, the average for goers was 74.02 CZK and 35.27 CZK for non-goers. If we go back to the thesis' main goal, the overall yearly value of the benefits of the Oskar Nedbal Theatre Tábor in the year 2012 amounts to 42,055,602 CZK, where $20.5 \%$ concerns the goers value and the remaining $79.5 \%$ non-goers value. The smaller proportion of the goers' value is caused by the above-mentioned fact that the theatre only has a narrow base of regular goers who frequent it several times a year. If we compare the value of benefits and the costs of subventions, which for the year 2012 are set to 8.941 million CZK, the benefit-cost ratio indicator achieved 4.7. Thus the value generated by the Oskar Nedbal Theatre Tábor in the year 2012 exceeds 4.7 times the subvention provided by the South Bohemian Region. In other words, for every crown the Oskar Nedbal Theatre Tábor receives from public funds, it generates a value of 4.7 crowns for the economy of the Tábor region. The net value amounts to $33,114,602$ CZK.

All in all, the study has brought optimistic results. Although the majority of people in the Tábor region do not go to the theatre, they would be willing to pay a certain amount for it. As has been mentioned in the theoretical part, the reason behind that may be to maintain the possibility of visiting the theatre in the future or simply the wish to maintain its existence although they are not planning to visit it. The possibility of using the method of contingent valuation was another positive aspect. Although the method has a lot of limitations, its use for the valuation of cultural institutions is becoming more frequent.

The question is whether it could be used for decision-making processes in the public sector, but the answer tends to be negative. For this purpose, the method is too time-consuming and the uncertainty of estimated value is considerable. Moreover, the specification of value should not be the only criterion the public sector considers when making decisions about cultural goods." (Kubíčková, 2012a).

\subsection{Analysis of Some Questions Concerning Valuation}

We can clearly see both the positives and the negatives of the methods used. The main trouble with the valuing methods used on the practical level to assess the theatre and museum in Tábor is their fragility against the relevance of responses. It is a classic economic dilemma faced by choice experiments always and just because they are experiments. The willingness to pay expressed nonbindingly in a survey does not have to, and surely will not, comply with the actual willingness to pay in reality. Yet there is a higher level to the issue. We are looking for such a valuation (calculation of value) that the people in a given region spontaneously ascribe to a cultural object; 
that means we are not actually looking for a sum they would be willing to pay, if they were invited to do so - from this angle the method used may seem flawless. According to the rules of the choice experiment thought concept, the presented values of the willingness to pay do reflect the value ascribed to a specific cultural object both by its users and non-users.

This "valuation game" would then really indicate the extent to which people appreciate some cultural goods, which indisputably is the purpose of the matter. In terms of a closed thought concept like this one, the suggested method is therefore suitable and brings quite interesting food for thought.

But still one cannot get rid of serious doubts.

The first problem arises with the "closed" system. In order to ascertain the relevancy of the presented benefit-cost ratio amounting to 4.7, we would have to provide an appropriate comparison with similar data from different areas - in our case, the only coefficients available are the one for the regional theatre and the one for the regional museum, which was determined by the same method (Kubíčková, 2012b) and amounts to 3.4. Compared to the actual volume of subventions, people of the Tábor region ascribe greater value to their theatre than to their museum. Such comparison is undoubtedly interesting, but we are still moving in a rather closed value system which ought to be tested from other aspects. That means finding out the same coefficient for other public services, such as the swimming pool, ice stadium, etc. When compared to values ascertained for other cultural or free-time venues, the two available coefficients would become more valuable and ready to be interpreted.

Although an interesting thing to find out, the value people ascribe to their theatre or museum or their willingness to pay for preserving both institutions will gain greater information value only when compared to the willingness to pay for other cultural goods.

In the subsequent research, a strict interpretation discipline will have to be followed when working with the results and determining what they actually mean. For instance, should the willingness to pay be studied only in relation to one cultural institution, one has to understand the response as a unique one, given regardless of the real economic background of an individual. In other words, merely as a theoretical personal appreciation of preserving the possibility to use such institution in the future.

\subsection{Particular Conclusions}

Despite all the gathered doubts, the method used in the quoted studies (Kubíčková, 2012ab) seems to allow us - at least basically - to find out an exceptionally interesting datum, that is the valuation of cultural goods by the public, both by the users and non-users of an institution.

If, sometime in the future, we were able to collect a larger amount of similar data, using statistically comparable methods and samples of respondents, we might - if nothing else - more or less objectively measure the development of the influence of cultural institutions on their direct and more distant environment. Of course, the changes of benefit-cost ratio depend on the actual sum of subventions or support from public resources, but the initial data, i.e. the declared willingness to pay for preserving certain cultural goods, are important as well. The development of the willingness would be an interesting way to measure whether the value of a cultural institution increases or decreases in the eyes of its users and non-users.

Should other attempts at similar research are carried out in the future we recommend some partial improvements, which do not mean we cast the above-mentioned results into doubt. Firstly, one 
should take into account not only direct subventions from public resources, but also add the tax that was not paid to the state in cases where cultural institutions are supported by donors (such as businesses). That would definitely increase the objectivity of collected data and improve the possibility of comparison.

However, we need to be aware that the chosen degree of supporting the creation of cultural goods is always a primarily political decision. Similarly, the way public resources are allocated is a political decision, too. In terms of economic assessment of the situation, we have to accept the fact that seen from the outside - the allocation will always be little representative and little transparent. Besides that, many steps certainly will not be realized, which would logically occur if we moved in a classic market environment. To demonstrate it, let us take the example of the Dejvice Theatre in Prague. According to available statistics (MCCR, 2011), for many years now the theatre has achieved an attendance rate of one hundred percent (for its own performances). From the economic point of view, the theatre (the company and creative team) should be transferred to a larger venue and a less successful company (in terms of attendance) should be transferred to the Dejvice Theatre. However, in the system of grants and subventions, such situation cannot occur for various reasons. It also means that this project's economic results cannot improve significantly, and the need for subventions shall remain - even if the benefit-cost ratio amounted to unusually high rates in this case. We need to admit, though, that if such theatre was not able to receive subventions and grants form public resources, its owner (be it an individual or business company) would make every effort and perhaps the necessary investment to promote sales of his product, which means transferring the company to a larger venue to get a bigger audience.

\section{ECONOMIC IMPACT OF THE EXISTENCE OF CULTURAL ORGANIZATION}

The assessment of direct and indirect impacts of the existence of a cultural organization (a funded work of art) offers more sensible results from an economic point of view. In reality, however, it too suffers from serious shortcomings. In its proposal for a pertinent certified methodology, the team of the above-mentioned Arts and Theatre Institute (Raabová, 2011), for instance, grants that: The presented methodology for the calculation of the economic impacts of cultural organizations is based upon an internationally recognized input/output analysis, which has at its disposal instruments for the quantification of mutual connections between subjects (branches or sectors) in the economy. In contrast to other methods, it enables also the quantification of multiplying effects that are caused by the connections of the organization examined and its visitors on other branches of the economy (the exit of one branch is at the same time often the entry of other branches of the national economy and vice versa). This is, of course, quite fundamental, although the authors in fact add: The presented method has been tested on several festivals in the CR, whilst it has been confirmed that its usage is suitable especially for large international projects that attract foreign visitors and, with them, also new incomes for the economy. This method cannot be fully applied for the calculation of local effects of cultural activities (impacts on the city and region), as the inputoutput model reflects the structure of the whole national economy, not the economy of the city or region. With a measure of tolerance, it is possible to estimate the direct impacts on the local economy (with the aid of direct coefficients), not the indirect (multiplying) effects.

Not even this method answers questions that the government and local authorities have posed to professional circles in recent years. After all, John Myerscough (1998), a classic of these methods, has shown that calculations of the impact of cultural institutions are more useful when gauging organizations with a large number of visitors and a national or at least above-regional significance; his critics have at the same time constructed quite significant theses that cast the method into doubt or transform it into an auxiliary method. Myerscough and others do indeed measure economic impacts, but they do not deal with the public aspect of matters in any way. From this point of view, 
the most substantial feat is that of film or musical production, which employs many people and attracts many visitors. This means that this is the calculation of impacts of funding the creative industry in the true sense of the word.

However, it says nothing about the social significance or aesthetic value of the work whatsoever or - from another angle - a successful test using Myerscough's methods (when the result shows strong multiplying effects on the level of economic impacts) can in fact show the popularity, superficiality and consumer character of the examined institute or cultural good. This means that a cultural or artistic work which is of consumer quality, but which mostly does not need practically any support from the state or municipality, will withstand a similar examination with the greatest success. In other words, funding a musical production is basically supporting a business project and not art in the sense art is usually understood.

\section{THIRD WAY}

There is yet another relevant method that can be incorporated into considerations regarding the potential creation of a certified method for evaluating cultural goods or works of art (or productions). This method involves examining the value that is placed on a particular work or good by its consumers, and perhaps also generally by the inhabitants of a region or country. This is a mechanism of creating a hypothetical market for goods that are not in the marketplace - for instance, cultural goods or institutions or also the demand for infrastructure or public interest in the case of environmental projects.

Simply put, we can ascertain how much people would be willing to pay for the above-mentioned good or work to be accessible, to be available to the public (WTP) or how much they would demand as compensation in case this good, institution or work were not available (WTA). In a contingent evaluation, we thus investigate the willingness to subsidize, and if such a will exists, the amount of subsidy which is considered adequate by the public (consumers and potential consumers). We might also ascertain how much consumers or potential consumers would expect as compensation if the good under examination were not available.

Understandably, this method too has several problematic areas and numerous critics. One of the evident problems is the fact that the respondents are aware that the answer is not binding; it therefore does not entail any promise of returning the declared sum or really gaining the demanded sum. This is to a large extent an intellectual game based on surveying public opinion through a standardized questionnaire survey. The second fundamental problem is a fact arising from the problem of the first - given that the survey is non-binding, respondents will have a tendency to answer in the sense of social expectation, i.e. they will overestimate even those cultural institutions and goods that in fact do not interest them whatsoever.

\section{CONCLUSIONS}

In the preceding sections, we have only summarized very approximately the basic problem of valuating cultural and artistic goods in terms of their significance and social influence as the only true gauge for evaluating the adequacy and efficiency of public funding.

If we were now to evaluate the conclusions very briefly, we would arrive at the conviction that it is in fact impossible to find a method (a certified method of valuating cultural goods), that would without modifications and specification be applicable to all areas of culture. Individual methods necessarily have to be distinguished - although the basic framework could be essentially identical. 
Furthermore, it seems that any method which should truly serve as a serious foundation to evaluate the efficiency of subsidizing cultural programs and grants would have to be multilayered; this means that it has to contain significant elements from all the above-mentioned methods.

Besides this, however, it is necessary to take into account the valuation provided by experts people knowledgeable in a certain area and whom we could consider to be experienced in this regard. Understandably, it is evident at first glance that implementing this idea would be inadequately expensive. Let us now model the procedure for institutions that traditionally elicit considerable embarrassment in Prague - that is, for theatres and theatre groups that receive severalyear grants from the city. Realizing a mere contingent evaluation would entail implementing a pertinent questionnaire not only for individual theatres separately, but also independently among groups of traditional viewers and incidental citizens (while it is quite probable that the "incidental citizen" will not be a regular or even an occasional theatre-goer).

In this respect, let me just mention a humorous result of a colleague's survey, in which he asked roughly one hundred students how often they and their family members went to the theatre. After converting the result to the number of inhabitants in the Czech Republic, it transpired that the total number of sold tickets in the country would have to be about fivefold against all really sold tickets and the number of viewers thus calculated would exceed by about threefold the number of seats available at the given time.

The contingent survey would nevertheless have to show the measure of "respect" commanded by the theatre among the public. In addition, we would probably have much to ascertain as regards the "media" success (familiarity) of the theatre in question and the degree to which at least a part of the public associates certain popular actors with the corresponding theatres. It should here be mentioned that the vast majority of theatres in the Czech Republic are grounded in the tradition of repertory theatre, with a stable group of actors and a traditional directional and dramaturgical foundation.

There are only a minimum of one-off productions or studios in the Czech Republic that are designated to produce a limited number of performances. Any contingent evaluation necessarily has to be supplemented by an analysis by selected experts, which naturally entails further expenses - at least if the statements are to be completely professional, expertly serious and also independent. Likewise, it is also necessary to use as a departure point further analysis, or an attempt must at least be made to evaluate the economic benefit of the functioning of theatres in a given area and in the whole context of the town or city. Even this, however, entails further costs for subsequent implementation of forthcoming economic decisions.

It would also be necessary to evaluate economic data for the funding period until then, investigate the influence of subsidies on the theatre's economy and further evaluate the theatre according to standard procedures. The results may seem absurd at first glance, but in the context of other information ascertained, they will become a logical basis for decision-making processes. And finally, the core of the problem itself cannot be forgotten, i.e. the attempt to estimate the extent to which the good or artistic institution fulfils its social objective. All of the above-mentioned procedures, including expert evaluation of general artistic quality, are only auxiliary tools that create a necessary contrast to this evaluation.

We are convinced that the foundation of this evaluation should be a comparison of potential attendance (maximum capacity) with actual attendance. Although many experts on art express doubts about this scale (again from the perspective of suspicion that what boasts high attendance need not necessarily be of high quality), we are convinced that this criticism can be eliminated with the aid of outputs from other elements of the evaluation as a whole. We also consider it absurd to 
compare absolute numbers of visitors; the relationship of capacity to reality appears to be more useful.

The methodology of comparing the number of visitors to capacity requires further processing, as the interpretation of the given numbers is a decisive element. In reality, however, we are convinced that if the pertinent data are analyzed to the fullest consistency - for instance, the attendance of individual performances, numbers of repeat performances and the assessment of their reception over a longer term, as well as in terms of real profits from sales against the original official price (to eliminate the influence of sales promotion) and further aspects, they can bring forward a lot of information decisive for assessing the efficiency of expended funds - of course, in connection with all the other above-mentioned information.

Any method for valuating cultural and artistic goods or institutions cannot bring results as objective as those available to valuate assets in the real market economy. Nevertheless, when expending considerable funds to collect necessary information and to analyze it, one can conceive of methods enabling to gain results in this area which could be relatively objective and would encompass the significance and social impact of cultural and artistic goods.

\section{Acknowledgment}

This work is one of the outputs of Effective methods of support for small and middle-sized subjects of cultural sector in environment of national and European economy (ID DF11P01OVV024) research project carried out by the Faculty of Business Administration, University of Economics in Prague, Czech Republic, under the Applied research and development of national and cultural identity Program (NAKI).

\section{REFERENCES}

Alpizar, F., Carlsson, F., \& Martinsson, P. (1998) Using Choice Experiments for Non-Market Valuation, Amsterdam: Springer.

Cikánek, M. (2009) Kreativní průmysly: př́ležitost pro novou ekonomiku, Prague: Arts and Theatre Institute.

Florida, R. (2002) The Rise of Creatice Class and How It's Transforming Work, New York.

Kant, I. (1965) Kritika soudnosti, Prague: Odeon.

Kislingerová, E. (2013) Několik poznámek k otázkám oceňování kulturních statků, Acta Oeconomica Pragensia, vol. 21, no. 1, pp. 46-60.

Kubíčková, K. (2012a) Ocenění Divadla Oskara Nedbala Tábor, Prague: University of Economics Prague.

Kubíčková, M. (2012b) Ocenění Husitského musea v Táboře, Prague: University of Economics Prague.

MC CR (2011) Základní statistické informace o kultuře v ČR, Prague: Ministry of Culture Czech Republic.

Myerscough, J. (1998) The Economic Importance of the Arts in Great Britain, London: Policy Studies Institute.

O'Brien, D. (2010) Measuring the value of culture: a report to the Department for Culture, Media and Sport, London: Department for Culture, Media and Sport.

Raabová, T. (2011) Návrh certifikované metodiky pro výpočet ekonomických dopadů kulturní organizace, Prague: Arts and Theatre Institute. 